\title{
Optimization of The Electrospinning Process for Preparation of Nanofibers From Poly (Vinyl Alcohol) (PVA) and Chromolaena odorata L. Extrac (COE)
}

\author{
I. Sriyanti ${ }^{1,2 *}$, L. Marlina ${ }^{1}$, J. Jauhari ${ }^{2}$ \\ ${ }^{1}$ Physics Education, Faculty of Education, Universitas Sriwijaya, Indonesia \\ ${ }^{2}$ Laboratory of Instrumentation and Nanotechnology Applications, Faculty of Computer Science, \\ Universitas Sriwijaya, Indonesia
}

Received: 24 January 2020. Accepted: 18 March 2020. Published: 30 June 2020

\begin{abstract}
The Cromaloena odorata (COE) contains phenols, flavonoids, tannins, alkaloids, saponins, steroids that possess diverse therapeutic effects. However, COE has poor solubility in water and poor absorbtion in the body. Incorporation of COE in nanofiber system is a promising way to increase CEO solubility. One of the method to produce nanofiber is electrospinning. The electrospinning process there are three of the most important process parameters are applied flowrate, voltage and TCD. In this study we developed optimized condition for electrospinning process of polyvinyl alcohol (PVA)/CEO and their characterization. The Scanning electron microscopy (SEM) analysis showed that modification of flowrate and TCD did not affect the morphology of PVA and COE fiber. However fiber diameter decreased when lower flowrate, higher voltage was applied, and TCD. Fourier Transform Infrared (FTIR) study was conducted to identify possible intermolecular interaction between PVA/COE that has potential application as antimicrobial wound dressing.
\end{abstract}

Keywords: Applied Flowrate; Chromolaena odorata Extract; Polyvinyl Alcohol; Tip-Collector Distance; Voltage

\section{INTRODUCTION}

Vinyl polymers such as Polyvinyrolidon $(P V P)$, polyvinylacetate (PVAc), and polyvinylalcohol (PVA) have been widely used for transdermal dressings and drug delivery devices (Park, Lee, \& Bea, 2008; Rasekh et al., 2014 Charernsriwilaiwat, Rojanarata, Ngawhirunpat, Sukma, \& Opanasopit, 2008). The former polymer is of particular interest since it is a hydrophilic polymer with excellent biocompatibility, spinnability, aqueous solubility and easiness for electrospinning process. Polyvinyl alcohol has demonstrated effectivity on controlling drug release and improving drug bioavailability of synthetic or natural compounds like emediom (Dai et al., 2012) and curcumin (Rahma et al., 2016).

Cromaloena Odorata $L$ is a popular leaf among Southeast Asians, including Indonesia. There has been a growing interest in croma-

${ }^{\star}$ Correspondence Address:

Jl. Prabumuli-Palembang Km 32 Inderalaya, Ogan Ilir 30662 E-mail: ida sriyanti@unsri.ac.id loena odorata leaf as herbal remedies for inflammation and infection. Cromaloena odorata leaf has been reported to contain phenols, flavonoids, saponins, terpenoids, tannins and steroids (Benjamin, 2015; Putri, \& Fatmawati, S. 2019; De Oliveira, Bernardi, \& Balbinot, 2017). Pharmacological activities of Cromaloena odorata leaf is in a wide range, from antifungal (Naidoo, Coopoosamy, \& Naidoo, 2011), antioxidant (Handayany, Umar, \& Ismail, 2018), Anti-plasmodial (Ezenyi, Salawu, Kulkarni, \& Emeje, 2014), anti-infammatory (Hanh, Hang, Van Minh, \& Dat, 2011), and antibacterial (Marianne, Lesatri, Sukandar, Kurniati, \& Nasution, 2014; Atindehou, Lagnika, \& Guerold, 2013) properties. Despite its huge potential, bioavaliablity of its essential bioactive substance (Cromaloena Odorata) is relatively low due to poor aqueous solubility and absorption (Benjamin, 2015; Putri, \& Fatmawati, S. 2019). The condition can cause no effects of cromaloena odorata compounds in the body. Incorporation of cromaloena odorata extrac into PVA-based nanofiber is therefore expected to enhance the 
solubility and bioavailability of cromaloena odorata.

One of the method to produce nanofiber is electrospinning (Sriyanti et al., 2017a; Sriyanti, Edikresnha, Munir, Rachmawati, \& Khairurrijal, 2017b; Munir, Suryamas, Iskandar, \& Okuyama, 2009; Sriyanti et al., 2018). In electrospinning process, the solution will be induced charge. The solution is usually loaded into a syringe and ejected from a needle which is connected to the high voltage source. If the electrostatic force is higher as the surface voltage with electric, the Taylor cone will be formed. When the electrostatic force from the electric charge is higher than the surface voltage, the emission from the end of the needle caused the liquid out of the nozzle towards the collector and produce the fiber that deposited on a grounded collector. The properties of nanofiber produced by electrospinning process is determined by several factors related to solution, process, and environment (Ramakrishna, Fujihara, Teo, $\mathrm{Lim}, \& \mathrm{Ma}, 2005)$. The solution parameters include the polymer molecular weight, viscosity, conductivity, and surface tension (Ramakrishna et al., 2005). A large number of studies has explored the solution parameter including variation of polymer concentration for production of vinyl polymer-based nanofiber, such as PVP/indomethacin (Rasekh et al., 2014), PVA/ meloxicam (Samprasit et al., 2015) and PVP/ GME (Sriyanti et al., 2017a; Sriyanti et al., 2018) for drug delivery system, also Chitosanethylenediaminetetraacetic acid/polyvinyl alcohol (CS-EDTA/PVA) for cosmetics (Charernsriwilaiwat, Rojanarata, Ngawhirunpat, Sukma, \& Opanasopit, 2013). However, there is no available information regarding electrospinning process for PVA/COE nanofiber with various process parameters including electric voltage, solution flow rate and TCD in the literature yet. The parameters are very important because it is associated with the fibers diameter and the molecular interaction between the polymer and the active substance.

In this study, we have evaluated the there important process parameters, spinning voltage, flow rate and TCD, on the morphology of the PVA/COE fiber In addition, we evaluated the intermolecular interaction in PVA/COE that has potential application as antimicrobial wound dressing.

\section{METHODS}

Methods. The research method has been used in this research is inductive method, that is started with literature study, observation (experiment and characterization) and analysis, while the synthesis method used is electrospinning method. The Electrospinning is the most versatile method for nanofibers syntheses. The Electrospinning offers great capability in producing fibers ranging from very small diameter to $100 \mathrm{~nm}$ or greater and presents good mechanical characteristics and controlled surfaces.

Materials. Poly(vinylalcohol), Cromaloena Odorata leaf (obtained from local market in Palembang, Indonesia), aqua demineralization from Palembang, and the ethanol from Bratachem, Indonesia.

Precursor solution preparation. PVA/ COE nanofiber was made from initial solution that has been prepared using in-situ method. $10 \%(\mathrm{w} / \mathrm{w})$ of COE was dissolved in aqual and stirred at $37^{\circ} \mathrm{C}$ for five hours. Separately, $10 \%$ $(\mathrm{w} / \mathrm{w})$ of PVA was dissolved in ethanol and stirred at $40^{\circ} \mathrm{C}$ for two hours. These two solutions were mixed to reach a mass ratio of PVA to $\mathrm{COE}$ of $10: 5$ and was stirred at $37^{\circ} \mathrm{C}$ for 60 minutes.

Electrospinning process. The homogenous solution was put into $10 \mathrm{ml}$ syringe with needle diameter of $0.8 \mathrm{~mm}$. The parameters for nanofiber synthesis process was optimized by varying the flow rate, voltage and TCD of solution. The setup of electrospinning process is shown in Figure 1. Three different flow rate were used: $0.1,0.5$ and $1 \mu \mathrm{L} /$ minute with constant voltage of $10 \mathrm{kV}$ and TCD of $12 \mathrm{~cm}$. For the optimization of voltage in PVA/COE electrospinning process, we varied the voltage at 10,14 and $18 \mathrm{kV}$ with constant flow rate of 0.5 $\mu \mathrm{L} /$ minute and TCD of $12 \mathrm{~cm}$. The TCD $(8,12$ and $16 \mathrm{~cm}$ ) with constants flow rate of $0.5 \mu \mathrm{L} /$ minute and voltage of $10 \mathrm{kV}$.

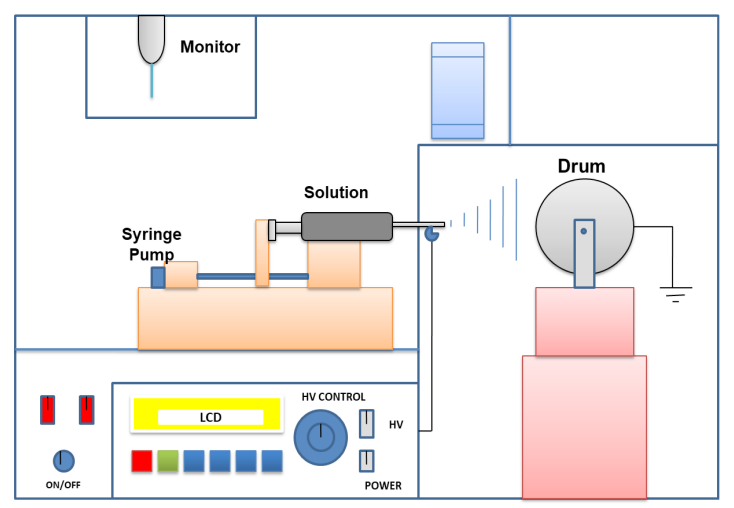

Figure 1. Electrospinning setup

The setup of electrospinning process is 
shown in Figure 1, consisting of a syringe pump to discharge polymer solution from the syringe needle, high voltage power supply to induce fiber formation, and a drum collector to collect fibers. In electrospinning technique, a high voltage is generated between the polymer solution contained in a syringe needle and drum collector. The polymer solution transformed from liquid phase to solid phase or fibers.

Morphology and Size. Scanning Electron Microscopy (SEM) technique was used to analyze the morphology of PVA/COE nanofibers. The fiber was coated with gold to improve conductivity. Image scanning was performed on scanning electron microscope (JEOL, JSM6560 ) at $15 \mathrm{kV}$ and 10000-fold optical magnification. SEM images were analyzed further for determination of fiber diameter. Average fiber size was obtained by measuring diameter of fiber taken from one hundred points using Image $\mathrm{J}$ software.

Physicochemical characteristics. Fourier Transform Infrared Spectroscopy (FTIR) was used to identify possible intermolecular interaction between PVA and COE. The $\mathrm{KBr}$ dics method was used for all PVA/COE fibers. Samples were analyzed eith FTIR spectrophotometer (Bruker, Alpha) and the spectrum scanning was perfomed from 500 to $4000 \mathrm{~cm}^{-1}$.

\section{RESULTS AND DISCUSSION}

\section{Electrospinning Process.}

The PVACOE solution of PVA/COE was formed into nanofiber via electrospinning process for 8-10 hours with various voltages and flowrates. In the electrospinning process, the charge will be induced into the solution when the needle is connected to a high voltage source. If the amount of charge is proportional to the surface tension it will form a Taylor cone. When the load exceeds the surface tension, there is an emission from the TID of the needle that causes the liquid to pull out of the tip of the needle. The charged jets undergo the process of withdrawal and will produce of fiber (Ramakrishna, 2005). The fibers collected on the rotating collector are PVA/COE nanofiber, can be seen in Figure 2. In general, physical appearance of PVA/COE nanofibers were marked by yellowish and smooth surfaced-mats. This showed that COE were perfectly blend into PVA matrix. Nanofiber was kept in an environmentally controlled storage condition (air-tight container, $30^{\circ} \mathrm{C}$ with $40-50 \%$ humidity). In general, physical appearance of PVA/COE nano- fibers were marked by yellowish and smooth surfaced-mats. This showed that COE were perfectly blend into PVA matrix. Nanofiber was kept in an environmentally controlled storage condition (air-tight container, $30^{\circ} \mathrm{C}$ with $40-55 \%$ humidity).

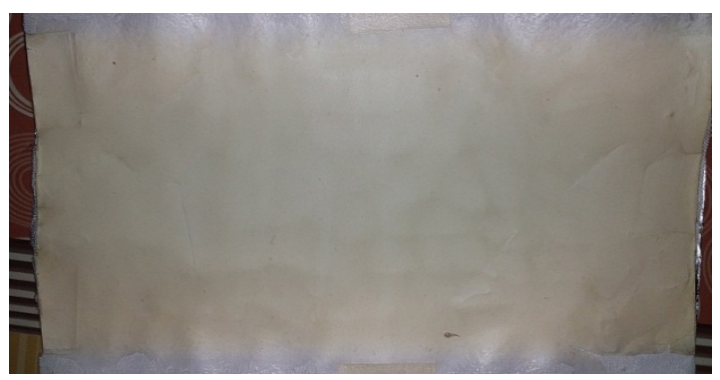

Figure 2. PVA/COE nanofiber produced from electrospinning method

\section{Effect of the electrospinning process para- meters to the fibers marfology of PVA/COE}

Optimization of flow rate in PVA/COE electrospinning process, the variation were 0.1 , 0.5 and $1 \mu \mathrm{L} /$ minute. Applied voltage, TCD, and the cylinder collector rotation were constantly maintained at $10 \mathrm{kV}, 12 \mathrm{~cm}$, and $50 \mathrm{rpm}$, respectively. Figure 3(a-c) shows SEM images $(x 10,000)$ of fibers resulted from various flow rate. It was found that the morphology did not change when the flow rate was modified. The resulting of marfology are bead-free fibers. This finding is consistent with previous study that reported increased flow rate produce bead-free fiber (Song et al., 2008). At higher flow rate, the marfology of nanofiber more bigger, because more solution is drawn to the collector during elecrospinning prosess (Ramakrishna et al., 2005). One of the important process parameter on the morphology of fiber formed is the applied voltage. The voltage associated with the charge transport in the solution during spinning process. In electrospinning, higher voltage is needed to induce the ejection of a liquid jet to form the Taylor cone (Ramakrishna et al., 2005; Sriyanti et al., 2017b). Figure 3 (d-f) shows SME images $(x 10,000)$ of PVA/COE with TCD of $12 \mathrm{~cm}$ and applied flow rate of $0.5 \mu \mathrm{L} / \mathrm{minu}-$ te. The applied voltage was varied from 10, 14, and $18 \mathrm{kV}$. From the SEM images, we found that increased applied voltage affected the fiber morphology and diameter. The nanofiber produced from voltage was $10 \mathrm{kV}$ condition had a long cyllindrical shape with no visible flaws such as beads or fragmented strands. When applied voltage increased to $14 \mathrm{kV}$ and $18 \mathrm{kV}$, there were slight changes in the morphology 
of resulted fiber. As the applied voltage increased further, the jet instability in Taylor cone was more obvious (Ramakrishna et al., 2005; Song, Kim, \& Kim, 2008). This instability was thought to be caused by side-jet addition formed from the solution suspended at the tip of the nozzle upon voltage induction. As a result, average fiber diameter decreased (Ramakrishna et al., 2005; Sriyanti et al., 2017a). Previous study has reported that an increase in applied voltage in polyvinyl acetate (PVAc)/ethanol (Song et al., 2008), caused a decrease in the fiber diameter.

The TCD is directly related to the magnitude of the electric field, the deposition of fibers deposition on the collector, and the evaporation of the solution. At short distance, the surrounding electric field will be larger hence reducing the time required for the fibers to be deposited on the collector and increase the rate of evaporation (Ramakrishna et al., 2005). Figure $3(\mathrm{~g}-\mathrm{i})$ shows the SEM images $(x 10,000)$ of PVA/COE with TCD variation. . The variation in TCD did not affect the morphology of the fibers and the nanofibers formed were still relatively uniform. Meanwhile, at a distance of $12 \mathrm{~cm}$, the fibers were more regularly uniform which then proved that this was the optimum distance to form fibers. Similar conditions have been reported by other researchers which stated that the distance between the needle and the collector will affect the formation of regular fibers (Sultana, Hassan, \& Lim, 2015)

\section{Effect of the electrospinning process para- meters to the fibers diameter of PVA/COE}

Although the morphology was not affected by low rate variation, fiber diameter was found to be dependent on flow rate, as shown in Figure 4(a-c). The diameter ranged from 150 to $1200 \mathrm{~nm}$ with average diameter of $428 \mathrm{~nm}$, 537 , and $619 \mathrm{~nm}$. The relationship between flow rate and fiber diameter was shown in Figure $4 a$. Average fiber diameter were larger as the flow rate increased. At higher flow rate, there are more solution suspended at the tip of the nozzle while elongation time is constant (Ramakrishna et al., 2005). This finding is consistent with previous study that reported increased PVAc fiber size due to increasing flow rate (Song et al., 2008).

As mentioned earlier, applied voltage not only affected fiber morphology but also fiber diameter. The average diameter of nanofiber at applied voltage of 10,14 , and $18 \mathrm{kV}$ were 537 , 504 , and $458 \mathrm{~nm}$, respectively. Increased ap- plied voltage resulted in smaller fiber diameter, as shown in Figure 4(d-f). Smaller diameter is a direct result of smaller Taylor cone, which is induced by higher voltage. At higher voltage, electrostatic force is stronger and thus Taylor cone formation occured on a higher rate, resulting in smaller cone jet volume (Ramakrishna et al., 2005 ). Therefore, we can conclude that variation of applied voltage affected fiber diameter by altering cone volume.

Another effect that occurred due to the changing distance between TCD was the diameter of the fiber. The distribution of fibers diameter can be seen in Figure 4(g-i). At the distance of 8,12 , and $14 \mathrm{~cm}$, the average diameters were $619 \mathrm{~nm}$ and $537 \mathrm{~nm}, 449 \mathrm{~nm}$, respectively. The relationship between the gap size to diameter of fibers is presented in Figure 4c. When the gap was large, the diameter of fibers was smaller. This happened since the increasing size of the gap will stretch the solution jet more since the travel time of the fibers will be longer as well (Ramakrishna et al., 2005).

\section{The effect of the process parameters to the molecular interaction of PVA/COE}

The infrared spectrum formed by PVA with molecular formula (C6H9NO)n can be seen in Figure $5 a$. The wide peak at wave number $3400 \mathrm{~cm}-1$ shows the $\mathrm{O}-\mathrm{H}$ stretching of hydroxyl group. The presence of PVA molecules was characterized by a sharp peak at wave number of $1659 \mathrm{~cm}-1$ which shows the $C$ $=\mathrm{C}$ stretching of cyclic amide groups and also the peaks at wave numbers of $816 \mathrm{~cm}-1$ which show the stretching of $\mathrm{C}-\mathrm{O}$ bend. The peak at wave number of $2840 \mathrm{~cm}-1$ and $2920 \mathrm{~cm}-1$ indicates the asymmetrical and anti-asymmetrical stretch of $\mathrm{CH} 2$ while the peak at wave number of $1365 \mathrm{~cm}-1$ shows the deformation of $\mathrm{S}=\mathrm{O}$ group (Awada \& Daneault, 2015; El-aziz,ElMagraby \& Taha, 2016). Meanwhile, the FTIR results of COE is also shown in Figure $5 a$. The peaks characteristic of COE can be observed at wave numbers 3342, 1639, 1453 and 1043 $\mathrm{cm}-1$ which respectively represent the strain of $\mathrm{O}-\mathrm{H}$ stretching of hydroxyl group, attributed to the presence of protein amide I, $\mathrm{N}-\mathrm{H}$ bending, and carbohydrate (C-O-C) (Alara, \& Abdurahman, 2019). In general, the spectra obtained from the COE indicated the presence of hydroxyl group showing the presence of phenolic compounds (Alara, Abdurahman, \& Ukaegbu, 2018).

FTIR is a technique to determine the IR absorption for identify specific functional group 

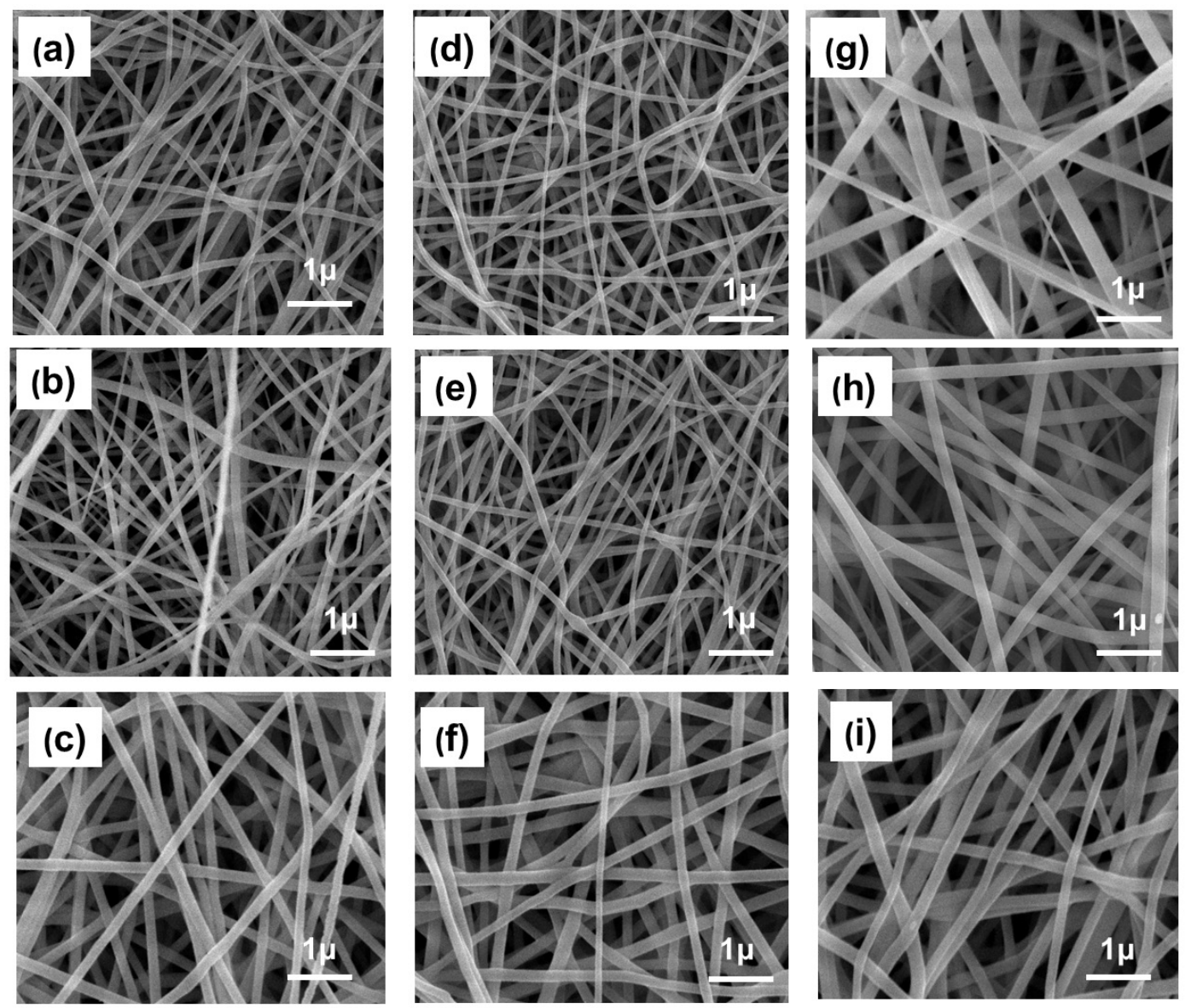

Figure 3. Scanning Electron Microscopic observation at massa rasio with variation of (a-c) flow rate $(0.1 \mathrm{~mL} / \mathrm{h}, 0.5 \mathrm{~mL} / \mathrm{h}, 1 \mathrm{~mL} / \mathrm{h}),(\mathrm{d}-\mathrm{f})$ voltage $(10 \mathrm{kV}, 14 \mathrm{kV}, 18 \mathrm{kV})$ and $(\mathrm{g}-\mathrm{i}) \mathrm{TCD}(8 \mathrm{~cm}, 12 \mathrm{~cm}$, $16 \mathrm{~cm})$

and the molecule interaction. Figure $5 \mathrm{~b}$ illustrated the FTIR spectrum of PVA/COE nanofiber with variatio flow rate $0.1,0.5,1 \mathrm{~mL} / \mathrm{h}$. An decreases in flow rate caused the peak shifting toward higher wavenumber from $3401 \mathrm{~cm}-1$ to $3395 \mathrm{~cm}-1$. This peak belongs to O-H stretching from the hydroxyl group that indicate as strong hydrogen chemical bond (Awada \& Daneault, 2015; El-aziz,El-Magraby \& Taha, 2016). A peak appeared around 2930-2932 $\mathrm{cm}-1$ was identified as asymmetric $\mathrm{C}-\mathrm{H}$ stretching from alkanes group. This peak became broader and the shifted to higher wavenumber. This indicated higher bonding energy between $\mathrm{C}-\mathrm{H}$. Additionally, a strong peak at $1590 \mathrm{~cm}-1$ assigned for $\mathrm{C}=\mathrm{C}$ stretching (aromatic) shifted to $1594 \mathrm{~cm}-1$. At $813 \mathrm{~cm}-1$, a peak of In-plane $\mathrm{C}-\mathrm{O}-\mathrm{S}$ bond from FFG1 nanofiber was observed. Peak shift of aromatic group indicated $\mathrm{C}=$ $C$ intermolecular interaction between COE and PVA. FTIR peak assignment for peak Assignment of PVA/COE nanofiber with variatio flow rate $0.1,0.5,1 \mu \mathrm{L} /$ minute are shown in Table 1 .
FTIR is a very useful technique to identify specific functional groups present in PVA/ COE fiber. The spectrum of variation voltage $10,14,18 \mathrm{kV}$ fiber are shown in Figure 5c. Peak assignment of variation voltage 10,14 , $18 \mathrm{kV}$ are summarized in table 1 . It was found that an increase in applied voltage caused shift of a number of peaks. In general, all fiber demonstrated a broad absorption band around $3100-3800 \mathrm{~cm}^{-1}$, which belongs to O-H stretching. However, this peak shifted toward lower wavenumber $\left(3374 \mathrm{~cm}^{-1} \rightarrow 3366 \mathrm{~cm}^{-1}\right)$ when applied voltage increased, indicating weak hydrogen bonding. This can be explained by theoretical assumption where the residue of solvent used in electrospinning process (ethanol or water) was lower when higher voltage was applied (Ramakrishna et al., 2005). Consequently, less hydroxyl groups was identified by FTIR (Rahma et al, 2016; Sriyanti et al., 2017b; Sriyanti et al., 2018). Additionally, the peaks appeared around $2800-3000 \mathrm{~cm}^{-1}$ was assigned for asymmetric $\mathrm{C}-\mathrm{H}$ stretching from 

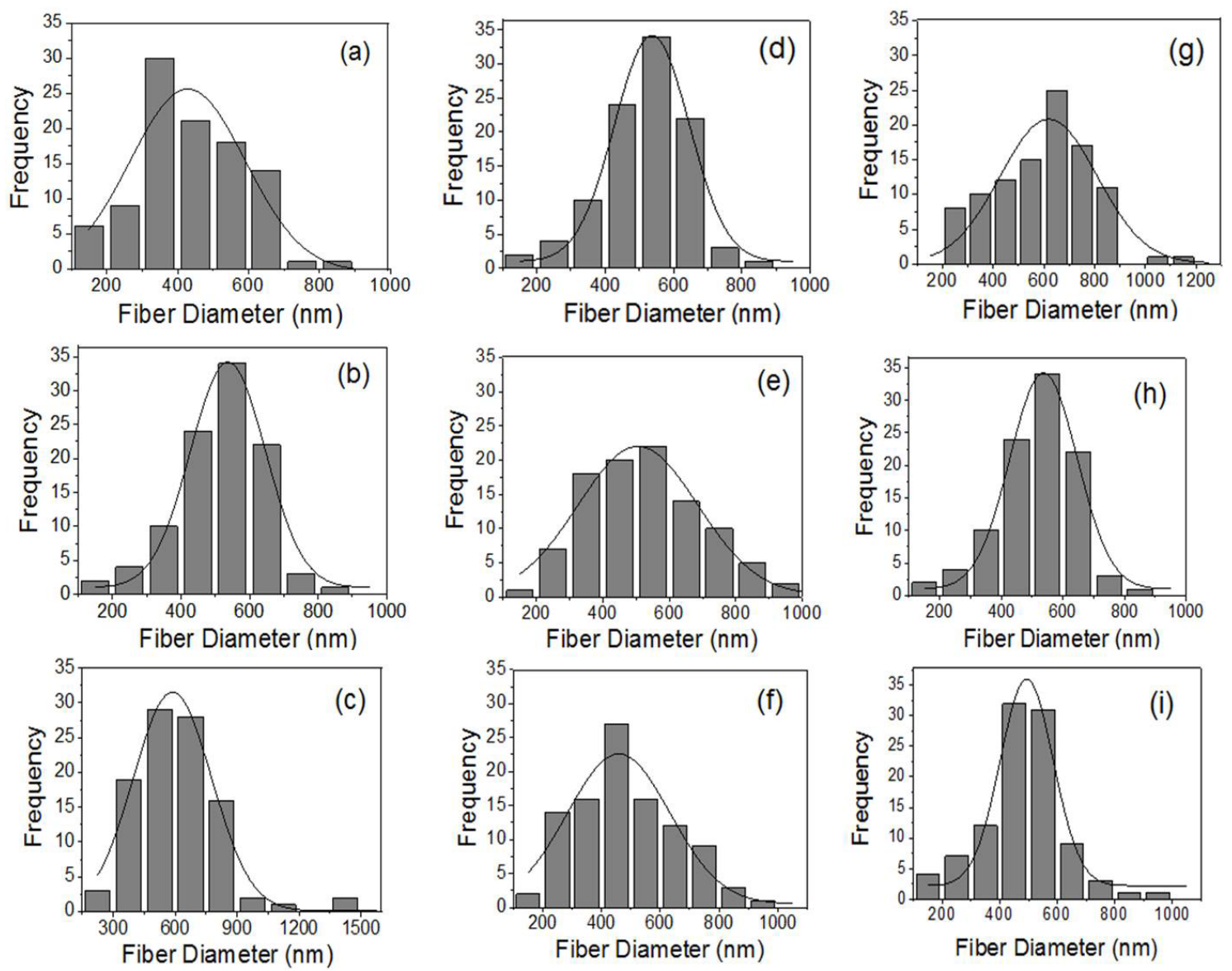

Figure 4. Fiber diameter with variation of (a-c) flow rate $(0.1 \mathrm{~mL} / \mathrm{h}, 0.5 \mathrm{~mL} / \mathrm{h}, 1 \mathrm{~mL} / \mathrm{h}$, (d-f) voltage $(10 \mathrm{kV}, 14 \mathrm{kV}, 18 \mathrm{kV})$ and $(\mathrm{g}-\mathrm{i})$ TCD $(8 \mathrm{~cm}, 12 \mathrm{~cm}, 16 \mathrm{~cm})$

Table 1. FTIR peak Assignment of PVA/COE nanofiber with variatio flow rate $0.1,0.5,1 \mu \mathrm{L} /$ minute (Awada \& Daneault, 2015; El-aziz,El-Magraby \& Taha, 2016)

\begin{tabular}{llll}
\hline $0.1 \mu \mathrm{L} /$ minute & $0.5 \mu \mathrm{L} /$ minute & $1 \mu \mathrm{L} /$ minute & Vibrational Mode \\
\hline 3401 & 3396 & 3395 & O-H stretching \\
2841 & 2842 & 2843 & Asymmetry stretch of $\mathrm{CH}_{2}$ pyrrole ring in alkanes \\
& & & Antiasymmetry stretch of $\mathrm{CH}_{2}$ pyrrole ring in al- \\
2930 & 2931 & 2932 & kanes \\
1590 & 1593 & 1594 & $\mathrm{C}=\mathrm{C}$ stretching (aromatic) \\
1365 & 1365 & 1366 & $\mathrm{~S}=$ O group \\
813 & 811 & 810 & In-plane C-O-S Bond \\
\hline
\end{tabular}

Table 2. FTIR peak Assignment of PVA/COE nanofiber with variation voltage 10, 14, $18 \mathrm{kV}$ (Awada \& Daneault, 2015; El-aziz,El-Magraby \& Taha, 2016)

\begin{tabular}{llll}
\hline $10 \mathrm{kV}$ & $14 \mathrm{kV}$ & $18 \mathrm{kV}$ & Vibrational Mode \\
\hline 3368 & 3379 & 3384 & O-H stretching \\
2844 & 2945 & 2945 & Asymmetry stretch of $\mathrm{CH}_{2}$ pyrrole ring in alkanes \\
2931 & 2931 & 2932 & Antiasymmetry stretch of $\mathrm{CH}_{2}$ pyrrole ring in alkane \\
1589 & 1580 & 1578 & $\mathrm{C}=\mathrm{C}$ stretching (alkenes) \\
1366 & 1366 & 1365 & $\mathrm{~S}=$ O group \\
818 & 817 & 817 & In-plane C-O-S Bond \\
\hline
\end{tabular}


(a)

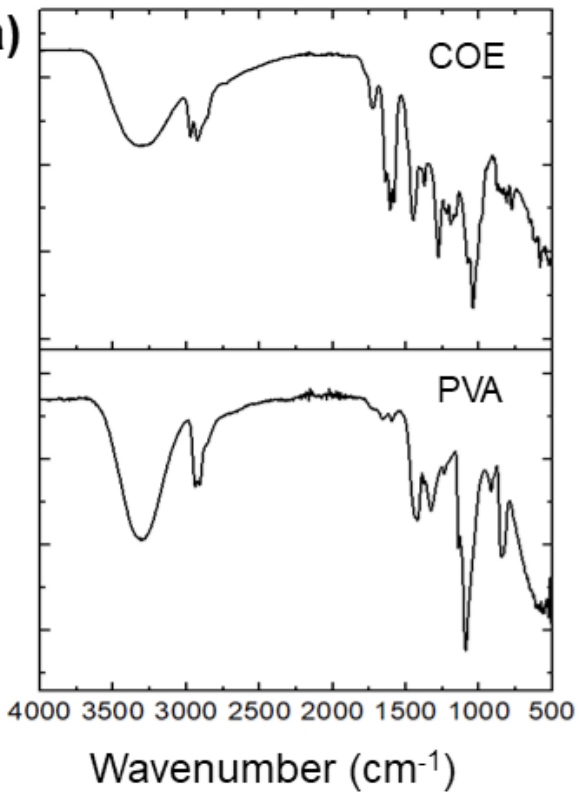

(b)

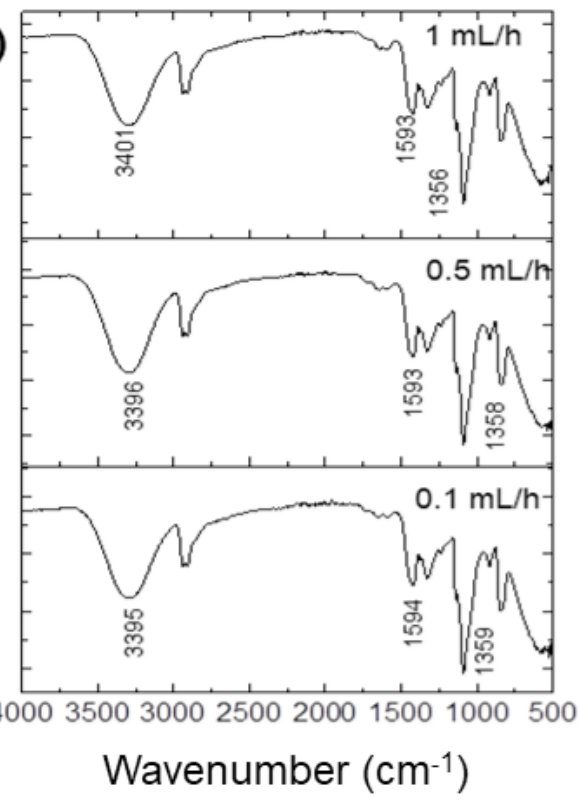

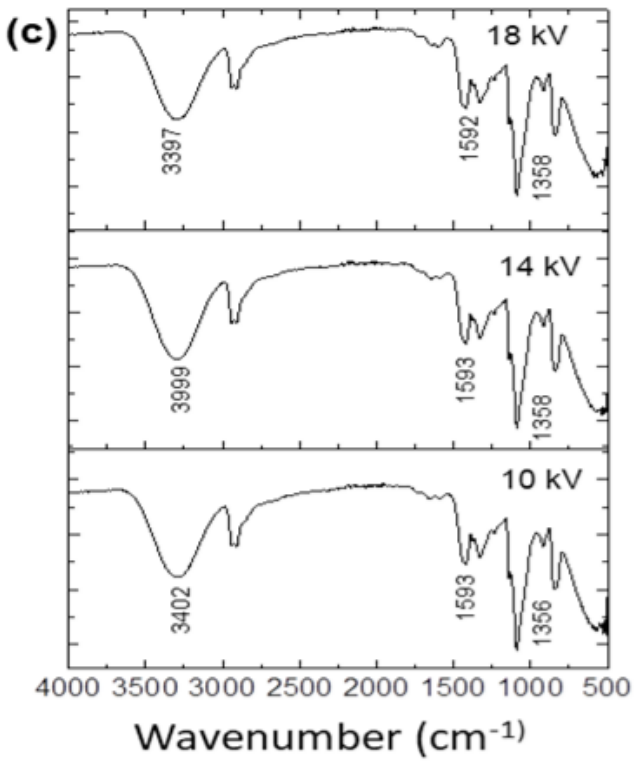

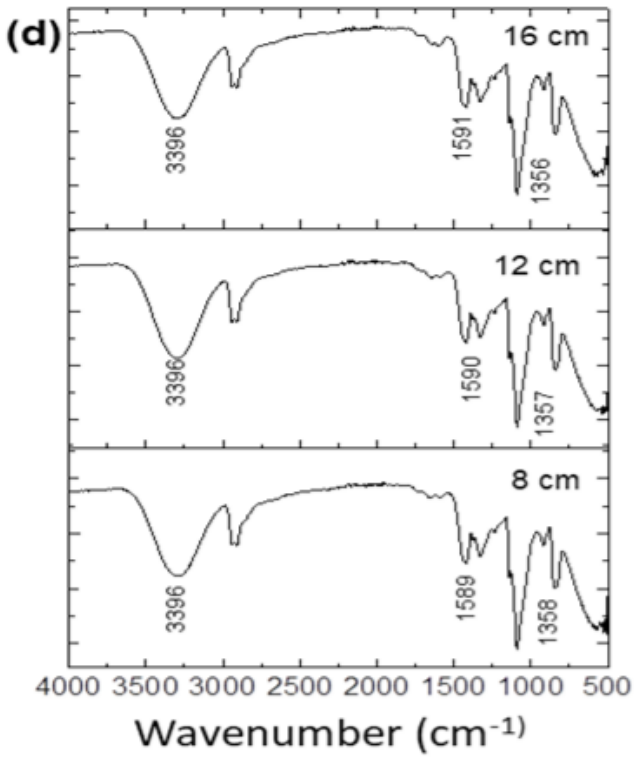

Figure 5. FTIR spectrum of (a) PVA powder and COE, (b) PVA/COE nanofiber; (c) variation flow rate $0.1,0.5,1 \mu \mathrm{L} /$ minute, (c) variation voltage $10,14,18 \mathrm{kV}$ and (d) variation TCD of $8,12,16 \mathrm{~cm}$

alkanes group. Higher applied voltage resulted in a broad peak with lower intensity and slightly shifted to lower wavenumber. This finding indicates lower energy bond between $\mathrm{C}-\mathrm{H}$. However, from Figure $5 \mathrm{c}$ it can be seen that other peaks were not affected by modification of applied voltage.

FTIR was used to detect specific groups of PVA/COE. Figure 5d shows FTIR spectra of the fibers with as the results of the varying distance between the needle to the collector at 8,12 and $16 \mathrm{~cm}$. The increasing gap size in the electrospining process shifted the peak of $\mathrm{OH}$ (hydroxyl group) bonding from $3992 \mathrm{~cm}$ to $3401 \mathrm{~cm}^{-1}$ and the peak of the $\mathrm{CH}_{2}$ pyrrole ring bonds (alkanes) from 2940 to $2943 \mathrm{~cm}^{-1}$. Hence, the wave numbers shifted from lower to higher wave numbers. This is due to the interaction and the formation of intermolecular hydrogen bonds between the functional groups and the PVA group and the functional group a group of COE. Meanwhile, with the increasing distance of the needle to the colector, the peak of $C=C$ shifted from $1589 \mathrm{~cm}^{-1}$ to $1578 \mathrm{~cm}^{-1}$. The peak of $\mathrm{C}=\mathrm{C}$ shifted toward higher wave numbers (meaning low energy). The disappe- 
Table 3. FTIR peak Assignment of PVA/COE nanofiber with varying TCD to be $8,12,16 \mathrm{~cm}$ (Awada \& Daneault, 2015; El-aziz,El-Magraby \& Taha, 2016)

\begin{tabular}{llll}
\hline $8 \mathrm{~cm}$ & $12 \mathrm{~cm}$ & $16 \mathrm{~cm}$ & Vibrational Mode \\
\hline 3392 & 3394 & 3401 & O-H stretching \\
2940 & 2942 & 2943 & Asymmetry stretch of $\mathrm{CH}_{2}$ pyrrole ring in alkanes \\
2951 & 2952 & 2952 & Anti-asymmetry stretch of $\mathrm{CH}_{2}$ pyrrole ring in alkanes \\
1592 & 1591 & 1591 & C=O stretching (alkenes) \\
1363 & 1362 & 1362 & C-H deformation from $\mathrm{CH}_{2}$ \\
810 & 811 & 811 & In-plane N-C =O Bend \\
\hline
\end{tabular}

arance of the peaks of amino group showed that the intermolecular hydrogen bonding in PVA and COE weakened further. The conclusion about FTIR analysis on the peaks of PVA/ COE with varying distance between the needle to collector can be seen in Table 3 .

\section{CONCLUSION}

Optimization of process parameter has resulted in nanofiber with excellent morphology. The increased applied voltage affected the fiber morphology and diameter, when applied voltage increased to $14 \mathrm{kV}$ and $18 \mathrm{kV}$, there were slight changes in the morphology of resulted fiber. Modification of flowrate and TCD were found to affect fiber diameter PVA/COE nanofiber. Fiber diameter decreased when higher voltage, lower flowrate and longer TCD was applied. The average diameter of nanofiber at applied voltage of 10,14 , and $18 \mathrm{kV}$ were 537,504 , and $458 \mathrm{~nm}$. The average diameter of nanofiber at flow rate of $0.1,0.5$ and $1 \mathrm{~mL} /$ jam were $428 \mathrm{~nm}, 537$, and $619 \mathrm{~nm}$. The average diameter of nanofiber TCD of of 8,12 , and $14 \mathrm{~cm}$ were $619 \mathrm{~nm}$ and $537 \mathrm{~nm}, 449 \mathrm{~nm}$. Higher applied voltage resulted in a broad peak with lower intensity and slightly shifted to lower wavenumber. The peak shift was thought to be a result of intermolecular interaction between PVA and COE via hydrogen bond formation. . However, further studies are required to investigate other aspects such as mechanical strength, physical and chemical degradation. In addition, processing condition for a larger scale might require further optimization.

\section{ACKNOWLEDGMENT}

This research was financially supported by Universitas Sriwijaya, Republic of Indonesia, under the University's Grant in the fiscal year 2020 .

\section{REFERENCES}

Abd El-aziz, M. A., El-Maghraby, A., Nahla A., \& Taha N. A. (2016). Comparison between polyvinyl alcohol (PVA)nanofiber and polyvinyl alcohol (PVA) nanofiber/hydroxyapatite (HA) for removalof $\mathrm{Zn} 2+$ ions from wastewater. Applied Sciences, 5, 840-850.https://doi. org/10.1016/j.arabjc.2016.09.025.

Atindehou, M., Lagnika, L., \& Guerold, B. 2013. Isolation and identifcation of two antibacterial agents from Chromolaena odorata L. active against four diarrheal strains. Advances in Microbiology, 03, 01, 115-121. https://doi. org/10.4236/aim.2013.31018

Alara, O.R., \& Abdurahman, N.H. (2019). GC-MS and FTIR analyses of oils from Hibiscus sabdariffa, Stigma maydis and Chromolaena odorata leaf obtained from Malaysia: Potential sources of fatty acids. Chemical Data Collections. https://doi.org/10.1016/j. cdc.2019.100200.

Alara, O.R., Abdurahman, N.H., \& Ukaegbu, C.I. (2018). Soxhlet extraction of phenolic compounds from Vernonia cinerea leaves and its antioxidant activity, Journal of Applied Research on Medicinal and Aromatic Plants. 11, 12-17. https://doi.org/10.1016/j.indcrop.2018.06.034

Awada, H., \& Daneault, C. (2015). Chemical modification of Poly(Vinyl Alcohol) in Water. Applied Sciences, 5, 840-850. https://doi:10.3390/ app5040840

Benjamin, V. (2011). Phytochemical and Antibacterial Studies on The Essential Oil of Euphatorium Odoratum. Pharmaceutical Biology. 227. ttps://doi.org//10.3109/13880208709060911

Charernsriwilaiwat, N., Rojanarata, T., Ngawhirunpat, T., Sukma, M., \& Opanasopit, P. (2013). Electrospun chitosan-based nanofiber mats loaded with Garcinia mangostana extracts. International Journal of Pharmaceutics, 452, 333-343. https://doi.org/10.1016/j. ijpharm.2013.05.012

Dai, X. Y., Nie, W., Wang, Y. C., Shen, Y., Li, Y., \& Gan, S. J. (2012): Electrospun emodin Polyvinyl alcohol blended nanofibrous membrane: A novel medicated biomaterial for drug delivery and accelerated wound healing. Journal 
of Materials Science: Materials in Medicine, 23 (11), 2709-2716. https://doi.org/10.1007/ s10856-012-4728-x

De Oliveira, J. A. M. ., Bernardi, D. I. ., Balbinot, R. B. (2017). Chemotaxonomic value of favonoids in Chromolaena congesta (Asteraceae). Biochemical Systematics and Ecology, 70,7-13 https://doi.org/10.1016/j.bse.2016.10.013

Ezenyi, I. C., Salawu, O. A ., Kulkarni, K., \& Emeje, M. (2014) . Antiplasmodial activity-aided isolation and identifcation of quercetin4'-methyl ether in Chromolaena odorata leaf fraction with high activity against chloroquine-resistant Plasmodium falciparum. Parasitology Research, 113, 12, 4415-4422. https://doi. org/10.1007/s00436-014-4119

Guo, M., Wang, X., Lu, X., Wang, H., \& Brodelius, P. E. (2016): $\alpha$-Mangostin Extraction from the native mangosteen (Garcinia mangostana L.) and the binding mechanisms of a-mangostin to HSA or TRF. PloS one, 11, e0161566. https://doi.org/10.1371/journal. pone. 0161566

Handayany, G.M., Umar, I., \& Ismail, S. (2018). Formulasi dan Uji Efektivitas Antioksidan Krim Ekstrak Etanol Daun Botto-Botto (Chromolaena Odorata L.) Dengan Metode Dpph. Jurnal Kesehatan, 11, 2.

Hanh, T. T. H. ., Hang, D. T. T.., Van Minh, C. ., \& Dat, N. T. (2011). Antiinfammatory efects of fatty acids isolated from Chromolaena odorata, Asian Pacifc Journal of Tropical Medicine, 4, 10, 760-763. https://doi.org/10.1016/S19957645(11)60189-2.

Marianne, Lesatri, D.P., Sukandar, E.Y., Kurniati, N.F., \& Nasution, S. (2014). Antidiabetic Activity of Leaves Ethanol Extract Chromolaena odorata (L.) R.M. King on Induced Male Mice with Alloxan Monohydrate. Jurnal Natural Unsyiah, 14, 1, 1-4. https://doi.org/10.24815/ jn.v14i1.1382

Munir, M. M., Suryamas, A. B., Iskandar, F., \& Okuyama, K. (2009): Scaling law on particle-to-fiber formation during electrospinning. Polymer, 50, 4935-4943. https://doi. org/10.1016/j.polymer.2009.08.01

Naidoo,K.K., Coopoosamy,R.M., \& Naidoo, G. (2011). Screening of Chromolaeana odorata (L.) king and robinson for antibacterial and antifungal properties. Journal of Medicinal Plant Research, 5, 19, 4859-4862.

Opanasopit, P., Ruktanonchai, U., Suwantong, O., Panomsuk, S., Ngawhirunpat, T., Sittisombut, C., Suksamran, T., \& Suphapol, P. (2008): Electrospun poly(vinyl alcohol) fiber mats as carriers for extracts from the fruit hull of mangosteen. Journal of Cosmetic Science, 59, 233-242.

Pothitirat, W., Chomnawang, M. T., \& Grtsanapan, W. (2010). Free radical and anti-acne activities of mangosteen fruit rind extracts prepared by different extraction methods. Phar- maceutical Biology, 48 (2), 182- 6 . https://doi. org/10.3109/13880200903062671

Palakawong, C., Sophanodora, P., Pisuchpen, S., \& Phongpaichit. (2010). Antioxidant and antimicrobial activities of crude extracts from mangosteen (Garcinia mangostana L.) parts and some essential oils. International Food Research Journal, 17, 583-9. https://doi. org/10.1016/j.proche.2014.12.027

Park, J. Y., Lee, I. H., \& Bea, G. N. (2008). Optimization of the electrospinning conditions for preparation of nanofibers from polyvinylacetate (PVAc) in ethanol solvent. Journal of Industrial and Engineering Chemistry, 14(6), 707-713. https://doi.org/10.1016/j. jiec.2008.03.006

Putri, D.A., \& Fatmawati, S. (2019). A New Flavanone as a Potent Antioxidant Isolated from Chromolaena odorata L. Leaves. EvidenceBased Complementary and Alternative Medicine. https://doi.org/10.1155/2019/1453612

Ramakrishna, S., Fujihara, K., Teo, W. E., Lim, T. C., \& Ma, Z. (2005): An introduction to electrospinning and nanofibers. World Scientific, Singapore, 3-118. https://doi. org/10.1142/9789812567611_0003

Rahma, A., Munir, M. M., Khairurrijal, Prasetyo, A., Suendo, V., \& Rachmawati, H. (2016). Intermolecular interactions and the release pattern of electrospun curcuminpolyvinyl(pyrrolidone) fiber. Biological and Pharmaceutical Bulletin, 39(2), 163-173. https://doi.org/10.1248/bpb.b15-00391

Rasekh, M., Karavasili, C., Soong, Y. L., Bouropoulos, N., Morris, M., Armitage, D., \& Ahmad, Z. (2014). Electrospun PVA-indomethacin constituents for transdermal dressings and drug delivery devices. International Journal of Pharmaceutics, 473(1-2), 95-104. https:// doi.org/10.1016/j.ijpharm.2014.06.059

Samprasit, W., Akkaramongkolporn, P., Ngawhirunpat, T., Rojanarata, T., Kaomongkolgit, R., \& Opanasopit, P. (2015). Fast releasing oral electrospun PVA/CD nanofiber mats of tastemasked meloxicam. International Journal of Pharmaceutics, 487(1-2), 213-222. https:// doi.org/10.1016/j.ijpharm.2015.04.044

Song, J. H., Kim, H. E., \& Kim, H. W. (2008). Production of electrospun gelatin nanofiber by water-based co-solvent approach. Journal of Materials Science: Materials in Medicine, 19(1), 95-102. https://doi.org/10.1007/ s10856-007-3169-4

Sriyanti, I., Edikresnha. D., Rahma, A., Munir, M. M., Rachmawati, H., \& Khairurrijal, K. (2017a). Correlation between Structures and Antioxidant Activities of Polyvinyl alcohol/Garcinia mangostana L. Extract Composite Nanofiber Mats Prepared Using Electrospinning. Journal of Nanomaterials. https://doi. org/10.1155/2017/9687896

Sriyanti, I., Edikresnha, D., Munir, M. M., Rach- 
mawati, H., \& Khairurrijal, K. (2017b): Electrospun Polyvinyl alcohol (PVA) nanofiber mats loaded by Garcinia mangostana L. extracts. Materials Science Forum, 880, 11-14.

https://doi.org/10.4028/www.scientific.net/ MSF.880.11

Sriyanti, I., Edikresnha. D., Rahma, A., Munir, M. M., Rachmawati, H., \& Khairurrijal, K. (2018). Mangosteen pericarp extract embedded in electrospun PVP nanofiber mats: physico- chemical properties and release mechanism of a-mangostin. International Journal of Nanomedicine. http://dx.doi.org/10.2147//JN. S167670Sultana, N., Hassan, M. I., \& Lim, M. M. (2005). Composite synthetic scaffolds for tissue engineering and regenerative medicine. Universiti Teknologi Malaysia. Johor bahru. https://doi.org/10.1007/978-3-31909755-8. 